\title{
Intercomparison of Two Fluorescent Dyes to Visualize Parasitic Fungi (Chytridiomycota) on Phytoplankton
}

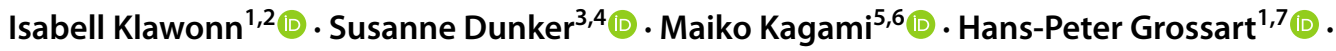 \\ Silke Van den Wyngaert ${ }^{1,8,9}$
}

Received: 22 July 2021 / Accepted: 4 October 2021 / Published online: 2 December 2021

(c) The Author(s) 2021, corrected publication 2022

\begin{abstract}
Fungal microparasites (here chytrids) are widely distributed and yet, they are often overlooked in aquatic environments. To facilitate the detection of microparasites, we revisited the applicability of two fungal cell wall markers, Calcofluor White (CFW) and wheat germ agglutinin (WGA), for the direct visualization of chytrid infections on phytoplankton in laboratorymaintained isolates and field-sampled communities. Using a comprehensive set of chytrid-phytoplankton model pathosystems, we verified the staining pattern on diverse morphological structures of chytrids via fluorescence microscopy. Empty sporangia were stained most effectively, followed by encysted zoospores and im-/mature sporangia, while the staining success was more variable for rhizoids, stalks, and resting spores. In a few instances, the staining was unsuccessful (mostly with WGA), presumably due to insufficient cell fixation, gelatinous cell coatings, and multilayered cell walls. CFW and WGA staining could be done in Utermöhl chambers or on polycarbonate filters, but CFW staining on filters seemed less advisable due to high background fluorescence. To visualize chytrids, $1 \mu \mathrm{g}$ dye $\mathrm{mL}^{-1}$ was sufficient (but $5 \mu \mathrm{g} \mathrm{mL} \mathrm{are} \mathrm{rec-}^{-1}$ ommended). Using a dual CFW-WGA staining protocol, we detected multiple, mostly undescribed chytrids in two natural systems (freshwater and coastal), while falsely positive or negative stained cells were well detectable. As a proof-of-concept, we moreover conducted imaging flow cytometry, as a potential high-throughput technology for quantifying chytrid infections. Our guidelines and recommendations are expected to facilitate the detection of chytrid epidemics and to unveil their ecological and economical imprint in natural and engineered aquatic systems.
\end{abstract}

Keywords Calcofluor White $\cdot$ Wheat germ agglutinin $\cdot$ Epifluorescence microscopy $\cdot$ Imaging flow cytometry $\cdot$ Microbial pathosystems

Isabell Klawonn

klawonn@io-warnemuende.de

Silke Van den Wyngaert

silke@uglylab.eu

1 Department of Experimental Limnology, Leibniz-Institute of Freshwater Ecology and Inland Fisheries (IGB), 12587 Berlin, Germany

2 Leibniz Institute for Baltic Sea Research (IOW), Seestrasse 15, 18119 Rostock, Germany

3 Department for Physiological Diversity, Helmholtz Centre for Environmental Research (UFZ), 04318 Leipzig, Germany

4 German Centre for Integrative Biodiversity Research (iDiv), 04103 Leipzig, Germany
5 Faculty of Science, Toho University, Funabashi, Chiba 274-8510, Japan

6 Faculty of Environment and Information Sciences, Yokohama National University, Yokohama, Kanagawa 240-8502, Japan

7 Institute of Biochemistry and Biology, Potsdam University, 14476 Potsdam, Germany

8 WasserCluster Lunz, Biologische Station, Dr. Carl Kupelwieser Promenade 5, 3293 Lunz am See, Austria

9 Department of Biology, University of Turku, Vesilinnantie 5, 20014 Turku, Finland 


\section{Introduction}

Parasitism —as a strong selective pressure in nature [1]—is one of the most dominating microbial interactions in plankton communities [2, 3]. Yet, microparasites are rarely considered in trophic interactions and biogeochemical processes in the aquatic environment, partly due to limitations in observing them in mixed microbial communities. Phytoplankton, which contributes to almost half of the primary production on Earth [4], is susceptible to various parasites [5]. For instance, members of the fungal division Chytridiomycota, referred to as chytrids, infect all major phytoplankton groups [6, 7], thereby altering the composition of phytoplankton communities [8-10], with cascading effects on microbial interactions and the flow of energy through aquatic food webs - a concept referred to as the fungal shunt [11] and mycoloop [12]. Moreover, chytrid epidemics may suppress the development of phytoplankton blooms $[8,13,14]$, potentially limiting the spread of harmful algae blooms [15] but also causing severe problems for algae mass culturing during feedstock or biofuel production [16, 17]. Chytrid epidemics thus profoundly affect ecosystem functioning with ecological and economic implications $[6,18,19]$.

Since the pioneering work on chytrids in British lakes [20], chytrids have been primarily studied locally in a few lakes and on a limited number of isolates [6], mostly because their small and inconspicuous thalli are frequently overlooked or misidentified by the untrained eye when using light microscopy. During the last decade, advances in DNA sequencing assays have substantially broadened the observed diversity and distribution of chytrids in aquatic habitats, reaching from highaltitude lakes [21], coastal regions [22, 23] to the deep-sea $[24,25]$ across various climate zones [7, 26-31]. This recently discovered diversity and biogeography, however, remains to be complemented with direct observations of chytrid abundances and host identities in most of those habitats.

Chitin-binding dyes, as markers for fungal cell walls, in combination with fluorescence microscopy are often used to determine infection prevalences, i.e., the proportion of host cells that is infected [32]. More recently, quantitative PCR (qPCR) [33], a chitin-binding probe [34], and fluorescence in situ hybridization (FISH) [35, 36] have been applied to detect chytrids. However, these three approaches have crucial limitations: qPCR has only been tested on free-swimming zoospores, so far, but not on host-associated sporangia [33], the previously used chitin-binding probe is not commercially available any longer, and FISH represents a rather expensive, low-throughput method. The use of chitin-binding dyes and fluorescence microscopy, therefore, remains the simplest and most widely used method to directly visualize chytrid-phytoplankton associations. Chitin-binding dyes include Calcofluor White (CFW), wheat germ agglutinin (WGA), Congo Red, Lactophenol-cotton blue, and Trypan
Blue [37]. Of those, CFW has been used most frequently [38], while WGA is the least toxic one. We thus focused on CFW and WGA, which both have been applied on pelagic [39] and benthic communities [37]. The fluorescent dye CFW binds nonspecifically to beta-1,3 and 1,4-linked polysaccharides which include chitin but also cellulose, the latter being present in cell walls of some phytoplankton taxa and fungi-like organisms, which can obscure chytrid detections [39]. The fluorescently-tagged lectin WGA instead binds specifically to $\mathrm{N}$-acetylglucosamine, i.e., the monomeric unit of the polymer chitin. Nevertheless, despite its specific chitin-binding properties, comparatively few studies have used WGA for chytrid staining [e.g., 40, 41].

To clarify the applicability of CFW and WGA in chytrid staining assays, we conducted a rigorous intercomparison of CFW vs. WGA staining on nine isolated pathosystems and field-sampled plankton communities. We were able to validate the staining of various morphological features of isolated chytrids during their life cycle. We further quantified the effect of different dye concentrations and sample storage times on the staining quality and verified the performance of CFW and WGA staining in combination with two widely used fixatives (Lugol and paraformaldehyde, PFA). Moreover, we demonstrate the application of WGA staining in combination with imaging flow cytometry as a potential set-up for high throughput quantification of chytrid infections. Finally, we offer guidelines for a CFW-WGA dual staining protocol, which we applied on natural plankton communities, to improve the detection of chytrid epidemics in diverse artificial and natural aquatic ecosystems.

\section{Materials and Methods}

Specifications and recipes of all chemical solutions, and a step-by-step staining protocol including epifluorescence microscopy are detailed in the supplementary information (Supplementary Text S1 and S2).

\section{Staining Various Morphological Features of Chytrids in Multiple Model Systems}

We grew nine taxonomically different host-chytrid pathosystems (Table 1) in batch cultures, as previously described (see Supplementary Text S3). Sub-samples of each co-culture were preserved with Lugol (alkaline, $10 \mu \mathrm{L} \mathrm{mL}^{-1}$ ) in 2-mL tubes and stored at $4{ }^{\circ} \mathrm{C}$ in darkness. Prior microscopy, samples were destained from Lugol by adding sodium thiosulfate $\left(\mathrm{Na}_{2} \mathrm{~S}_{2} \mathrm{O}_{3}\right.$, final conc. $\left.7.6 \mathrm{mM}\right)$ [42] and thereafter dual stained with CFW and WGA (Fluorescent Brightener 28 and WGA-Alexa Fluor ${ }^{\mathrm{TM}} 488$ Conjugate) for $15 \mathrm{~min}$ in the dark ( $5 \mu \mathrm{g} \mathrm{mL}^{-1}$ of each dye). The dual staining was justified since no competitive staining was observed herein and 
Table 1 Model pathosystems used for comparative CFW and WGA staining, including their isolation date and location. References (Ref.) include the chytrid descriptions (if available). Genbank accession numbers are listed in the Supplementary (Table S3)

\begin{tabular}{|c|c|c|c|c|c|}
\hline Host-chytrid system & Taxa & ID & Date & Location & Ref. \\
\hline \multirow[t]{2}{*}{ Asterionella formosa - Rhizophydiales sp. \#1 } & Diatom & AST-A1 & Nov-2016 & Lake Stechlin (GER) & - \\
\hline & Rhizophydiales & AST-CHY1 & Dec-2016 & Lake Stechlin (GER) & \\
\hline \multirow[t]{2}{*}{ Ulnaria sp. - Zygophlyctis planktonica } & Diatom & HS-SYN2 & Apr-2015 & Haussee (GER) & [43] \\
\hline & Zygophlyctidiales & SVdW-SYN-CHY1 & Feb-2016 & Melzersee (GER) & \\
\hline \multirow[t]{2}{*}{ Staurastrum sp. - Chytridiales sp. } & Desmid & STAU-ULLS3 & Sep-2017 & Ullswater (GBR) & - \\
\hline & Chytridiales & STAU-CHY RBA3 & Oct-2017 & Rimov reservoir (CZE) & \\
\hline \multirow[t]{2}{*}{ Staurodesmus - Rhizophydiales sp. \#2 } & Desmid & STAU-ULLS2 & Sep-2017 & Ullswater (GBR) & - \\
\hline & Rhizophydiales & STAU-CHY6 & Sep-2017 & Dormant water (GBR) & \\
\hline \multirow[t]{2}{*}{ Staurastrum sp. -Rhizophydiales sp. \#3 } & Desmid & STAU-ULLS3 & Sep-2017 & Ullswater (GBR) & - \\
\hline & Rhizophydiales & STAU-CHY RBA5 & Oct-2017 & Rimov reservoir (CZE) & \\
\hline \multirow[t]{2}{*}{ Staurastrum sp. - Staurastromyces oculus } & Desmid & STAU1 & Oct-2014 & Lake Stechlin (GER) & [44] \\
\hline & Rhizophydiales & STAU-CHY3 & Jul-2015 & Lake Stechlin (GER) & \\
\hline \multirow[t]{2}{*}{ Eudorina elegans - Algomyces stechlinensis } & Green algae & PAN1 & Oct-2014 & Lake Stechlin (GER) & [45] \\
\hline & Lobulomycetales & SVdW- EUD3 & Dec-2015 & Lake Stechlin (GER) & \\
\hline \multirow[t]{2}{*}{ Yamagishiella unicocca - Dangeardia mamillata } & Green algae & PAN4 & Oct-2014 & Lake Stechlin (GER) & [45] \\
\hline & Incertae sedis & SVdW- EUD2 & Jul-2015 & Lake Stechlin (GER) & \\
\hline \multirow[t]{2}{*}{ Yamagishiella unicocca - Endocoenobium eudorinae } & Green algae & PAN4 & Oct-2014 & Lake Stechlin (GER) & [45] \\
\hline & Polyphagales & SVdW- EUD1 & Jun-2015 & Lake Stechlin (GER) & \\
\hline
\end{tabular}

earlier [39, 41], allowing for a direct comparison of both dyes in the same sample. Stained chytrids were evaluated in Utermöhl chambers on the same day under an inverted fluorescence microscope (Nikon Eclipse Ti2, used throughout this study and therefore referred to as microscope in the following) at $600 \times$ magnification using two fluorescence channels (WGA: $482 / 35 \mathrm{~nm}$ excitation/536/40 nm emission, CFW: $377 / 50$ excitation/415 LP emission).

The life cycle of chytrids involves various development stages and morphological features, which we addressed by validating the staining patterns on those multiple features (Fig. 1A). Features included (1) encysted zoospores (i.e., initially attached zoospores), (2) immature sporangia (larger than encysted zoospores but not yet matured, no visible zoospores), (3) mature sporangia (zoosporangia with visible zoospores inside), (4) empty sporangia (cell wall remains of the sporangia after zoospore discharge), (5) resting spores (resting stages with thickened cell walls), (6) rhizoids (rhizoidal structures inside the host cell), and (7) stalks (extensions of the sporangia to physically attach to the host's cell wall). In addition, we examined encysted, immotile, freely suspended zoospores [i.e., not attached to any host cell, in contrast to (1)] which were only present in the Yamagishiella-Endocoenobium system. Of each morphological feature, 25 events (in 15 out of 96 instances 5-20 events) were evaluated in parallel with both fluorescence channels. The staining patterns were qualitatively evaluated and assigned to three categories: (1) entirely stained, i.e., the entire morphological feature displayed a bright, homogeneous fluorescent signal, 2) partly stained, i.e., the morphological feature did not display a homogeneous fluorescent signal or the fluorescence was weaker compared to other morphological structures of the same species, and 3) not stained, if no fluorescent signal was detectable. Additionally, we evaluated the staining patterns on live cells (no Lugol-preservation) in three selected systems (Asterionella-Rhizophydiales, Ulnaria-Zygophlyctis, and Staurastrum-Staurastromyces).

\section{Dye Concentrations, Storage Times, and Sample Preservation/Preparation Types}

Using the Asterionella-Rhizophydiales \#1 co-culture, we validated the effect of different dye concentrations and storage times on the enumeration of chytrid and host cells, and their emitted fluorescence intensity. Three different CFW and WGA concentrations $\left(1,5\right.$, and $25 \mu \mathrm{gL}^{-1}$, storage overnight) and storage times ( 1 day, 4 weeks, and 6 months, dye concentration was $5 \mu \mathrm{g} \mathrm{mL}^{-1}$ ) were tested. Since infection prevalences are commonly determined by enumerating encysted zoospores and sporangia [14], we verified the staining of those structures, if not indicated differently.

Samples were either preserved with Lugol (alkaline, 10 $\mu \mathrm{L} \mathrm{mL} L^{-1}$ ) and inspected in Utermöhl chambers or preserved with paraformaldehyde (PFA, final conc. $1.5 \%$, fixation overnight) and inspected on polycarbonate filters (PC, $0.2 \mu \mathrm{m}$, $25 \mathrm{~mm}$ )—hereafter Lugol- and PFA-preserved samples, respectively (see Supplementary Figure S1 for a schematic 

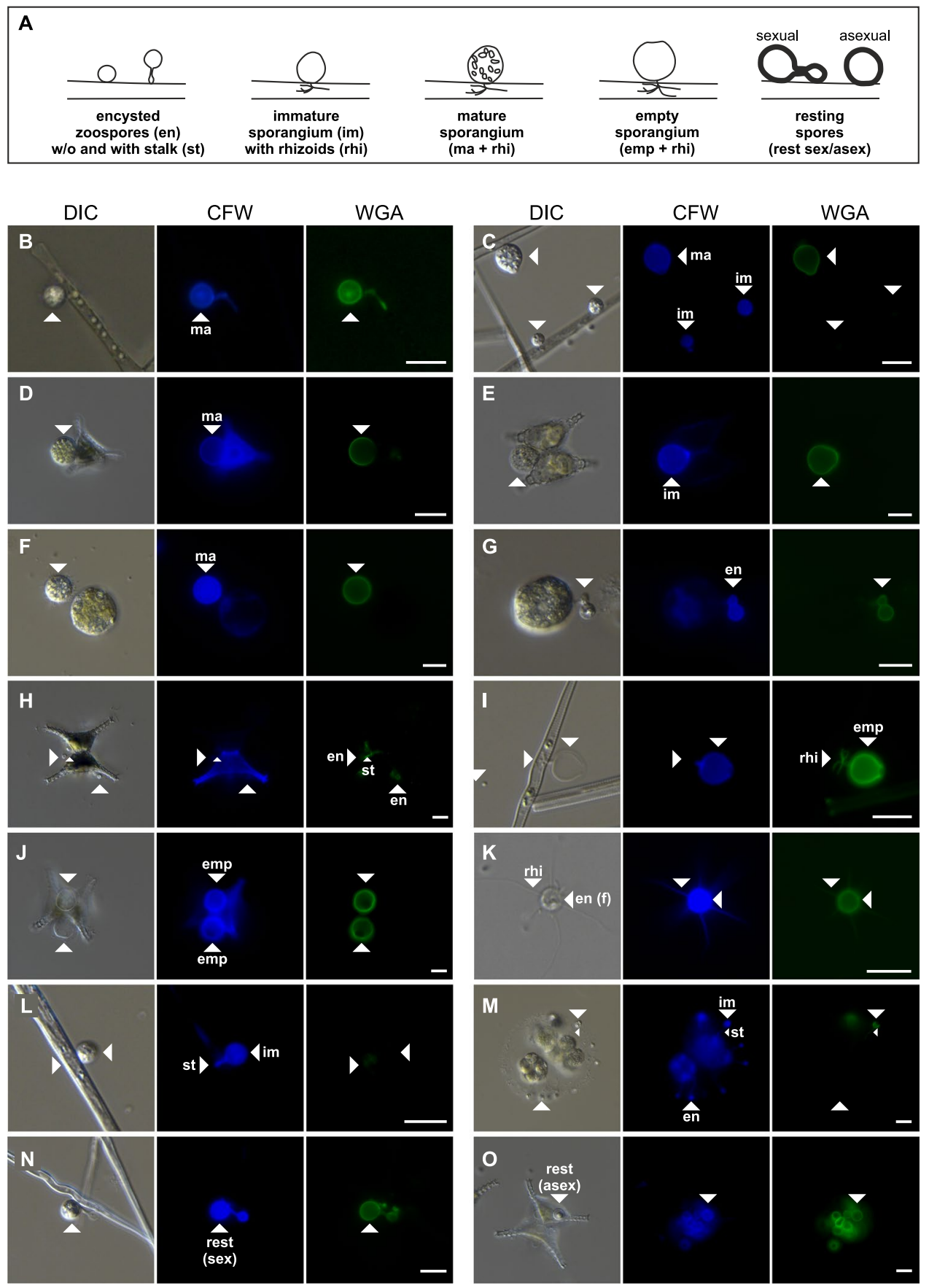

Figure. 1 (A) Scheme of various morphological features during the life cycle of parasitic chytrids. Infections emerge as free-living, motile zoospores settle and encyst onto a phytoplankton cell [46]. After encystment, the parasite penetrates and expands into the host's interior via hyphae-like rhizoids, through which nutrients are conveyed from the host to the parasite. The host-derived nutrients nurture the exterior structure to a mature sporangium, which produces and releases new zoospores into the ambient water upon maturation, leaving behind an empty sporangium. To overcome periods of low host abundances, many chytrids can produce resting spores, sexually [46] or asexually [44]. (B-O) Microscopy images of various phytoplankton-chytrid model systems used for the comparative CFW and

WGA staining (data shown in Fig. 2). B Asterionella-Rhizophydiales \#1, C, I, L, N Ulnaria-Zygophlyctis, D, H, J Staurastrum-Chytridiales, E Staurastrum-Staurastromyces, $\mathbf{F}, \mathbf{M}$ Eudorina-Algomyces, $\mathbf{G}$ Yamagishiella-Endocoenobium, and $\mathbf{O}$ Staurastrum-Rhizophydiales. $\mathbf{K}$ shows the rather uncommon zoospores of Endocoenobium, which develop immotile spores with a cell wall and rhizoid-like structures for host attachment. White scale bars are $10 \mu \mathrm{m}$. Abbreviations: DIC differential interference contrast. CFW Calcofluor White, WGA wheat germ agglutinin, en-encysted zoospores (host-associated), en (f) - encysted zoospores (freely suspended, not host-associated), im/ ma-immature/mature sporangia, emp —empty sporangia, rest (sex/ asex)—resting spores (sexual/asexual), rhi—rhizoids, st—stalks 
workflow). In this way, we minimized the exposure of the applicant to toxic volatile PFA during sample preparation and microscopy. In addition, we stained live cells (no preservation, day 0), applying the same staining protocol as for Lugol-preserved samples but without Lugol addition. Lugolpreserved samples were stored in 2 -mL tubes at $4{ }^{\circ} \mathrm{C}$, while PFA-preserved samples were stored on filters at $-20{ }^{\circ} \mathrm{C}$. Prior microscopy, Lugol-preserved samples were destained from Lugol and stained with CFW and WGA, as described above but with separate CFW and WGA staining (no dual staining). PFA-preserved cells were stained in liquid and thereafter filtered onto PC filters if cells were analyzed immediately; or, if stored at $-20{ }^{\circ} \mathrm{C}$, cells were filtered first and thereafter stained on the filter. In the latter case, the filters were submerged in the dye solution for $15 \mathrm{~min}$ in darkness and washed twice with $1 \mathrm{~mL}$ CHU-10 medium and $1 \mathrm{~mL}$ MilliQ to remove excess dye, followed by air-drying.

Chytrid sporangia and Asterionella cells were counted in triplicates under the microscope at $300 \times$ magnification, using three fluorescence channels (CFW: 387/11 excitation/442/46 emission, WGA: 482/35 nm excitation/536/40 nm emission, and chlorophyll autofluorescence: $635 / 18 \mathrm{~nm}$ excitation/680/42 $\mathrm{nm}$ emission). In total, we counted $~ 300-1,200$ Asterionella cells (non-infected and infected) and $\sim 50-500$ encystments/sporangia per replicate ( $n=3-4$ chambers or filters). Since single Asterionella cells could carry multiple infections, we report the ratio of total host cells to chytrid infections (the latter defined as the sum of encysted zoospores and im-/mature sporangia) instead of reporting the infection prevalence (which does not account for multiple infections on single host cells). CFW-stained filters displayed a high background fluorescence, which precluded the determination of meaningful sporangia counts. $\mathrm{CFW}$-stained sporangia were consequently not analyzed on filters (but in Utermöhl chambers).

After counting, we imaged the fluorescent signal of WGA-stained sporangia and chlorophyll-autofluorescent Asterionella cells. CFW-stained sporangia were also imaged but the CFW images turned out to be overexposed, and thus, they were not used for any further data processing. We took 20 z-stack images $(521 \times 521 \mu \mathrm{m}, 0.4 \mu \mathrm{m}$ increments over $10-15 \mu \mathrm{m}$ depth, Nikon DS-Ri2 camera, $16 \mathrm{MP}$ ) per replicate ( $n=3-4$ chambers or filters), each image covering several Asterionella colonies with and without infections. Images were always taken with the same settings (e.g., light intensity, gain, and exposure time), except that the autofluorescent signal of Lugol-preserved Asterionella cells was amplified through a higher gain (20.9x) as compared to PFA-preserved cells $(1.8 \times$ gain $)$. This higher gain was chosen since the autofluorescence of Lugol-preserved cells was otherwise poorly visible. Fluorescence intensities of WGAstained sporangia and autofluorescent Asterionella cells were analyzed on the mono-color images from the WGA and chlorophyll autofluorescence channels, respectively. Each z-stack was merged to a composite image with one focal plane (NISElements AR software, v. 5.01.00, function: extended depth of focus) and further processed in ImageJ (v.1.51p) [47]. In ImageJ, color images were converted into 16-bit images, followed by thresholding to separate bright foreground pixels (fluorescent sporangia or Asterionella cells) from dark background pixels. The fluorescence intensity in the hereby separated cells was analyzed as mean grey values via particle analysis (function: analyze particles). Only chytrid cells and Asterionella cells emitted a fluorescence above the threshold on the WGA and chlorophyll-autofluorescent images, respectively, and thus only those cells were included in the final data set.

\section{Imaging Flow Cytometry of WGA-Stained Sporangia}

A sub-sample of the WGA-stained Asterionella-Rhizophydiales co-culture (no fixative, $5 \mu \mathrm{g} \mathrm{WGA} \mathrm{mL}^{-1}$ ) was pre-filtered through a $100 \mu \mathrm{m}$ cell strainer, to avoid clogging the tubes of the flow cytometer (Asterionella colonies were mostly $<100 \mu \mathrm{m}$ ). The filtrate was split into two-one for flow cytometry and one for microscopy analyses. Flow cytometry was conducted with an imaging flow cytometer (ImageStream ${ }^{\circledR X}$ MK II, Luminex Corporation, US) equipped with three lasers $(488 \mathrm{~nm} / 200$ $\mathrm{mW}, 561 \mathrm{~nm} / 200 \mathrm{~mW}$, and $785 \mathrm{~nm} / 80 \mathrm{~mW}$ ) and two CCD-cameras [48, 49]. Measurements were performed with laser intensities of $488 \mathrm{~nm} / 1 \mathrm{~mW}, 561 \mathrm{~nm} / 40 \mathrm{~mW}$, and $785 \mathrm{~nm} / 0.5 \mathrm{~mW}$ [the intensity of the $561 \mathrm{~nm}$ laser was reduced by a neutral density-filter (optical density 1.0), and $40 \mathrm{~mW}$ refers to the original laser intensity]. Dulbecco`s phosphate-buffered saline without calcium and magnesium (Biowest, Nuaillé, France) was used as a sheath-fluid. For each triplicate, $\sim 50 \mu \mathrm{L}$ were analyzed automatically at $200 \times$ magnification $(120 \times 512 \mu \mathrm{m}$ field of view, numeric aperture 0.5 , pixel size $1 \times 1 \mu \mathrm{m})$. Data acquisition with the INSPIRE software (v. 201.1.0.693) was finished when 1,000 events (including Asterionella cells and associated sporangia but excluding speed calibration beads) were measured. Infections were counted based on the images for WGA fluorescence ( $488 \mathrm{~nm}$ excitation, 528/65 nm emission), brightfield, and autofluorescence (488 $\mathrm{nm}$ excitation, $702 / 85 \mathrm{~nm}$ emission) using the IDEAS software (v. 6.2.187.0). As a direct comparison, Asterionella cells and associated sporangia were counted in Utermöhl chambers (triplicates) via microscopy, as described above. CFW-stained sporangia were not analyzed via imaging flow cytometry since the instrument was not equipped with a UV laser, as this laser has a shorter lifetime and is more expensive than the ones used herein. 


\section{CFW and WGA Staining of Field-Sampled Communities}

Mixed plankton communities were sampled with a plankton net (HydroBios, $25 \mu \mathrm{m}$ mesh size) from surface waters (0-5 m) in a mesotrophic lake (Lake Stechlin, 53 $08^{\prime} 34.6^{\prime \prime} \mathrm{N}$ and $\left.13^{\circ} 01^{\prime} 41.9^{\prime \prime} \mathrm{E}\right)$ and a coastal station in the Baltic Sea $\left(54^{\circ} 08.76 ' \mathrm{~N}\right.$ and $11^{\circ} 50,58^{\prime} \mathrm{E}$, salinity $8-20 \%$, both Northern Germany) in 2018, 2020 and 2021, fixed with Lugol and stored at $4{ }^{\circ} \mathrm{C}$. Before microscopy, samples were dualstained ( $5 \mu \mathrm{g}$ dye $\mathrm{mL}^{-1}$, after destaining from Lugol), as described above, and inspected in Utermöhl chambers at 200-400 × magnification. We were able to detect 1-156 sporangia per phytoplankton taxon, which were evaluated in parallel for their positive WGA and CFW-staining. A stepby-step protocol for the dual-staining method, and statistical analyses are included in the supplementary information (Text S2 and S4).

\section{Results}

\section{Effectivity of CFW and WGA Staining for Various Morphological Features of Chytrids}

Morphological features of chytrids in the model systems showed a similar CFW and WGA staining pattern after dualstaining, with some exceptions (Figs. 1 and 2). Encysted zoospores and sporangia were visible to $\geq 90 \%$ with both dyes in most systems. As an exception, encysted zoospores and im-/mature sporangia in the Ulnaria-Zygophlyctis, Yamagishiella-Dangeardia, and Yamagishiella-Endocoenobium systems were stained (entirely or partly) to $0-80 \%$ with WGA, while CFW stained those features to $\geq 90 \%$ (e.g., Fig. 1C and L for Ulnaria-Zygophlyctis, and $1 \mathrm{G}$ for Yamagishiella-Endocoenobium, Fig. 2). Empty sporangia associated with post-infected host cells were stained with both dyes to $100 \%$ in all systems. Resting spores and rhizoids, if present, were mostly more effectively stained with WGA (10-100\%) than with CFW (0-100\%). In four out of nine model systems, stalks were part of the chytrid morphology and they were stained with CFW (80-100\%) and WGA (20-100\%). Free-swimming zoospores commonly do not have a chitinous cell wall and they are, therefore, not stained by chitin-binding dyes. Zoospores of Endocoenobium, however, encyst freely in the water and develop a special type of immotile spores with a cell wall and rhizoid-like structures through which they attach to their motile host [45]. Those immotile infectious spores were entirely or at least partly stained with CFW and WGA (Fig. 1K, data are not included in Fig. 2 since this feature was only observed in one pathosystem).

Interestingly, host-associated encysted zoospores and im-/mature sporangia were stained differently in live vs. Lugol-preserved samples in the three tested pathosystems. WGA failed to visualize those features in live samples of Staurastrum-Staurastromyces and Ulnaria-Zygophlyctis, whereas the staining was successful after Lugol preservation

\begin{tabular}{l}
$\begin{array}{l}\text { Model pathosystem } \\
\text { (host - chytrid) }\end{array}$ \\
Asterionella formosa - \\
Rhizophydiales sp. \#1 \\
Ulnaria sp. - \\
Zygophlyctis planktonica \\
\hline Staurastrum sp. - \\
Chytridiales sp. \\
\hline Staurodesmus - \\
Rhizophydiales sp. \#2 \\
\hline Staurastrum sp. - \\
Rhizophydiales sp. \#3 \\
\hline Staurastrum sp. - \\
Staurastromyces oculus \\
\hline Eudorina elegans - \\
Algomyces stechlinensis \\
\hline Yamagishiella unicocca - \\
Dangeardia mamillata \\
\hline Yamagishiella unicocca - \\
Endocoenobium eudorinae
\end{tabular}
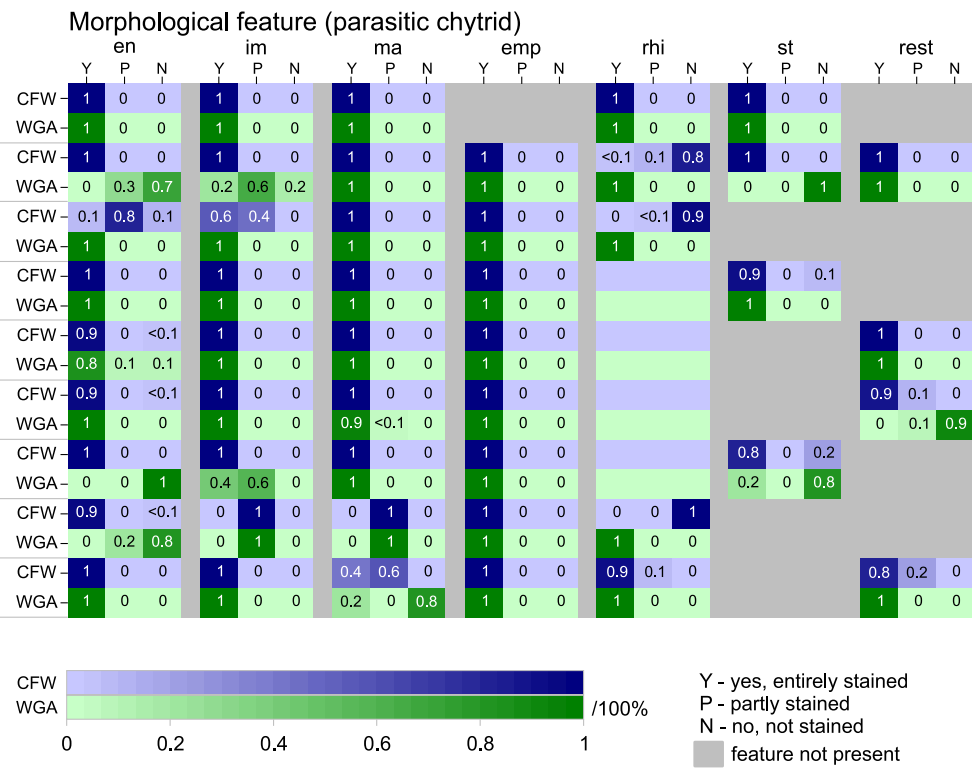

Fig. 2 Effectivity of CFW and WGA staining for various morphological features of chytrids indiverse phytoplankton-chytrid model systems. The color scale and detailed numbers indicate the fraction of entirely/partly stained or unstained features. In four pathosystems, rhizoids were presumably present but not visible after staining (no numbers given). Grey boxes indicate features that could not be tested for their staining patterns since they were not developed by the chytrids in our samples. Empty sporangia of Rhizophydiales on Asterionella dissolved after zoospore discharge and could thus not be evaluated. Abbreviations are defined in the caption of Fig. 1 
(Fig. 3). In the Asterionella-Rhizophydiales system, such a different staining pattern was not apparent since WGA visualized encysted zoospores and sporangia in both live and Lugol-preserved samples. In contrast to WGA, CFW stained encysted zoospores and sporangia in both live and Lugolpreserved samples in all three systems (Supplementary Figure S2). Empty sporangia were stained with CFW and WGA in live and Lugol-preserved samples in all three systems.

\section{Dye Concentrations and Storage Times, Utermöhl (Lugol) vs. Filter (PFA), and Microscopy vs. Flow Cytometry (Asterionella-Rhizophydiales System)}

The mean ratio of total Asterionella cells to chytrid infections (i.e., the sum of encysted zoospores and im-/mature sporangia) was $2.9 \pm 0.4$ (mean \pm s.d., $n=87$ ). This ratio was independent of the dye concentration $\left(1-25 \mu \mathrm{g} \mathrm{mL}^{-1}\right.$, $p>0.05, \mathrm{Df}=8$ ) and storage time ( 1 day -6 months, $p>0.05$, Df $=7$, Kruskal-Wallis H-test, Fig. 4A, B). The intensity of the green fluorescence of WGA-stained sporangia was rather similar across different dye concentrations and storage times (Fig. 4C, D). Intensities of the green fluorescence of WGAstained sporangia were lower on PC filters (PFA-preserved) than in Utermöhl chambers (Lugol-preserved, $p<0.05$, Kruskal-Wallis, Df=4). Nonetheless, WGA-stained sporangia were well distinguishable from the background fluorescence on/in both filters and Utermöhl chambers. The diatom's autofluorescence was highest in live samples, and if a fixative was added, it was better preserved by PFA than by Lugol.

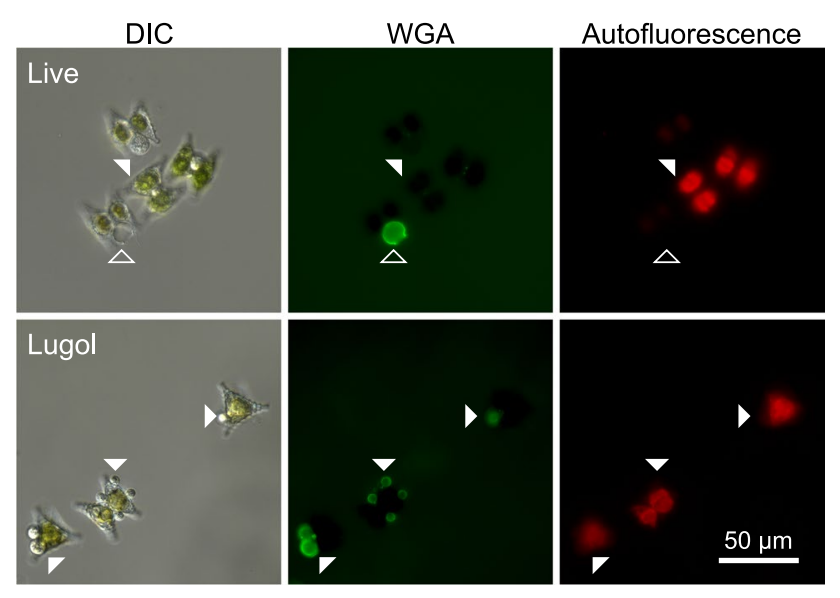

Fig. 3 Micrographs depicting the WGA staining pattern in the Staurastrum-Staurastromyces pathosystem in live (no preservation) and Lugol-preserved samples. In live samples, WGA visualized empty but not mature sporangia (non-filled and filled arrowheads, respectively). In Lugol-preserved samples, by contrast, mature sporangia were stained with WGA. See Supplementary Figure S2 for exemplary CFW images. DIC - differential interference contrast, WGA-wheat germ agglutinin
In addition to microscopy, we successfully enumerated WGA-stained sporangia in the Asterionella-Rhizophydiales model system via imaging flow cytometry. Cells were well recognizable on the bright field, autofluorescence, and WGA images (Fig. 5A). Consequently, flow cytometry and microscopy yielded similar estimates for host abundances and infection prevalences (host abundances: 125,571 $\pm 12,232$ and $116,354 \pm 12,592$ cells $\mathrm{mL}^{-1}, p=0.50$, infection prevalence: $22 \pm 2$ and $23 \pm 2 \%, p=0.63, \mathrm{Df}=5$, respectively, $t$-test, Fig. 5B).

\section{CFW and WGA Staining of Field-Sampled Chytrid Sporangia}

In field-sampled plankton communities, we observed sporangia associated with diverse phytoplankton taxa, mostly including cyanobacteria and diatoms (Table 2). As a key difference between dyes, WGA effectively illuminated chytrid sporangia that were associated with the dinoflagellates Peridinium and Ceratium. By contrast, CFW brightly stained the cellulosic thecae of those dinoflagellates, thereby preventing the visualization of the associated sporangia (Supplementary Figure S3). The dual-staining was successful in limnic and oligo-/mesohaline water.

\section{Discussion}

Chytridiomycota appear almost pervasive in freshwater and coastal marine environments as their detection in recent DNA sequencing assays has substantially ramped up their diversity and biogeography [28, 41, 50-53]. Hence, to quantify their ecological and economical imprint, there is a need to detect chytrid-phytoplankton associations via direct observations. Our methodological discussion therefore aims to facilitate a simple, reliable, and standardized screening of chytrid infections in various microplankton communities during case studies and routine monitoring programs.

\section{Intercomparison of CFW and WGA Staining}

The staining patterns of various morphological features in the model systems were similar yet not identical for CFW and WGA. In live samples, WGA did not stain encysted and im-/mature sporangia in the Staurastrum-Staurastromyces and Ulnaria-Zygophlyctis cultures (Fig. 3). Those phytoplankton cells and chytrid sporangia were presumably coated with a polysaccharide-rich mucilage [54, 55], which results from the secretion of polymeric substances from phytoplankton [55-59] and chytrid cells [60]. Such cell coatings may limit the accessibility of WGA to the fungal cell walls since WGA is a large macromolecule $(\sim 35 \mathrm{kDa})$, which poorly diffuses into gelatinous coatings (mucilage) of 


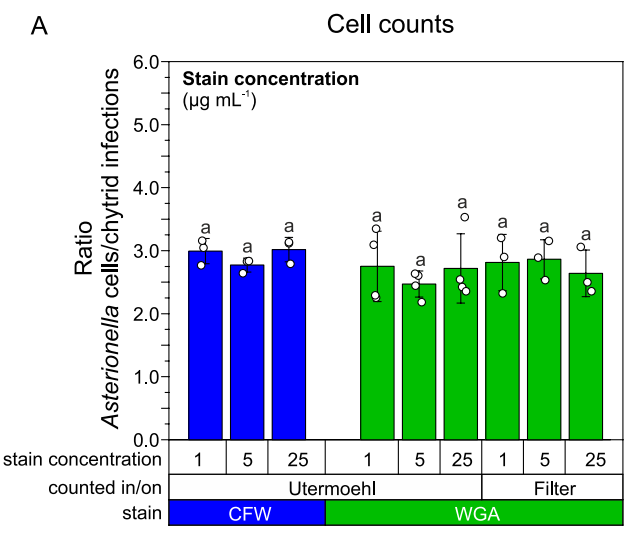

B

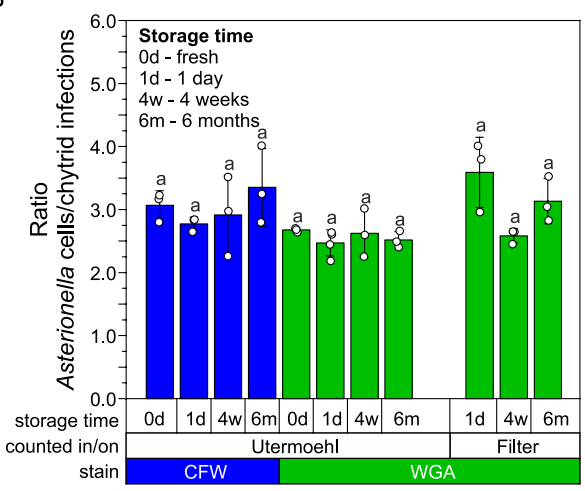

Fig. 4 Microscopy analyses of the Asterionella-Rhizophydiales pathosystem after CFW and WGA staining using different dye concentrations $(\mathbf{A}, \mathbf{C})$ and sample storage times $(\mathbf{B}, \mathbf{D})$. A and B Cells were counted in Utermöhl chambers (Lugol fixation) and on polycarbonate filters (PFA fixation). Samples from day 0 represent live samples (no preservation). Shown are mean \pm s.d. $(n=3-4$, s.d. $\leq 22 \%)$. C and D Fluorescence intensity emitted by WGA-stained sporangia and chlorophyll-autofluorescent Asterionella, determined via image analyses. Statistical differences in the data distribution between different groups are indicated by different letters $(a-d$, Kruskal-Wallis test,
C
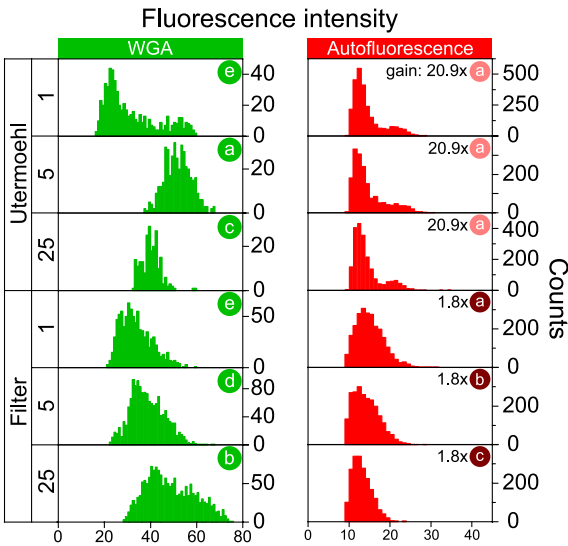

D

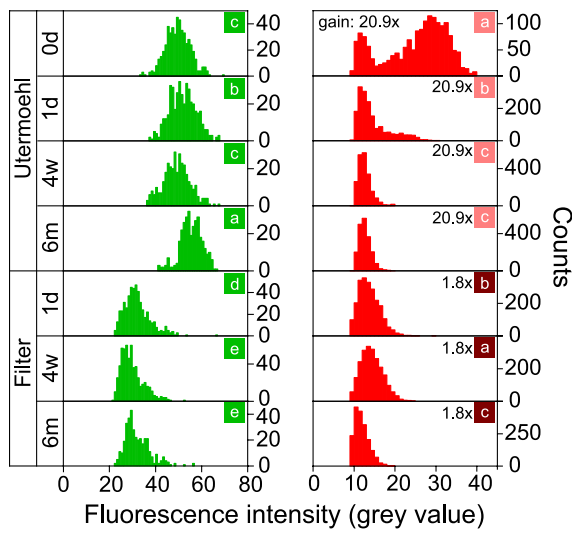

$p>0.05)$. Multiple group comparisons were run separately for WGAstained sporangia and chlorophyll-autofluorescent Asterionella cells at different dye concentrations and storage times in Utermöhl chambers and on filters (indicated by the different colors and symbols). The chlorophyll autofluorescence of Lugol-fixed Asterionella cells was rather low compared to PFA-fixed cells, and thus, Lugol-fixed cells in Utermöhl chambers were imaged at a higher gain $(20.9 x)$ than PFA-fixed cells on filters 1.8x. Fluorescence data of CFW-stained sporangia are not shown due to overexposure (i.e., cells displayed max. color values)
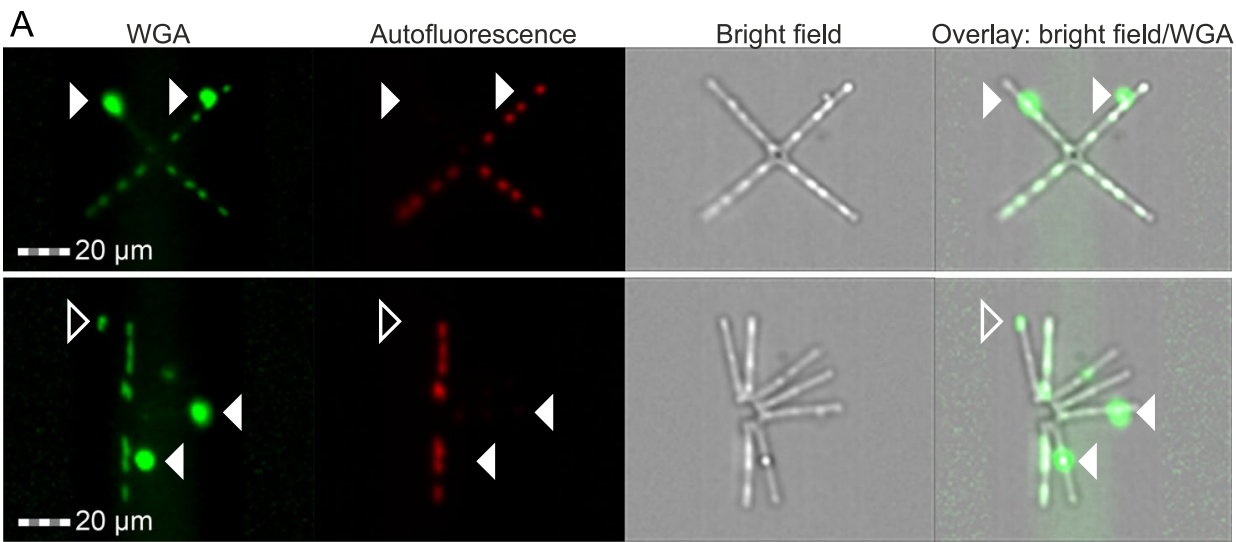

B

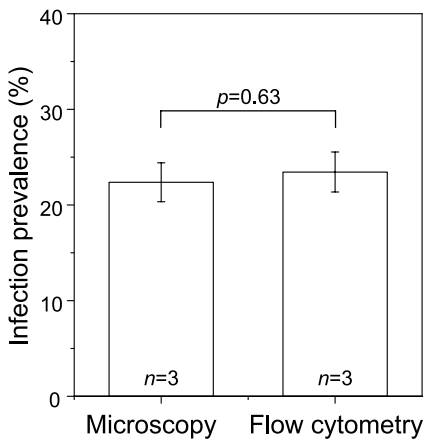

Fig. 5 A Visualization of WGA-stained sporangia in the Asterionella-Rhizophydiales pathosystem via imaging flow cytometry. The green fluorescence (WGA) depicts mature sporangia (filled arrowhead) and one post-infected Asterionella cell with rhizoids (open arrowhead). B The obtained infection prevalence was statistically not significantly different between microscopy and flow cytometry analyses $(t$-test, $p=0.63, D f=5)$ 
Table 2 Dual-staining of chytrid sporangia that were associated with various phytoplankton taxa in natural water

\begin{tabular}{|c|c|c|c|c|}
\hline \multicolumn{2}{|l|}{ Phytoplankton } & \multicolumn{2}{|c|}{ No. of sporangia } & \multirow{2}{*}{$\begin{array}{l}\text { Sampling date } \\
\mathrm{dd} / \mathrm{mm} / 20 \mathrm{yy} *\end{array}$} \\
\hline Group & Genus & CFW & WGA & \\
\hline Cyanobacteria & Planktothrix & 156 & 146 & 18/04/18 (LS) \\
\hline Cyanobacteria & Pseudanabaena & 61 & 61 & 25/08/18 (LS) \\
\hline Cyanobacteria & Dolichospermum (heterocytes) & 6 & 6 & 25/08/18 (LS) \\
\hline Cyanobacteria & Dolichospermum (vegetative cells) & 6 & 5 & 25/08/18 (LS) \\
\hline Cyanobacteria & Dolichospermum (vegetative cells) & 40 & 40 & 06/07/21 (BS) \\
\hline Diatoms & Cerataulina & 40 & 40 & 01/12/20 (BS) \\
\hline Diatoms & Chaetoceros & 40 & 40 & $13 / 10 / 20(\mathrm{BS})$ \\
\hline Diatoms & Fragilaria & 40 & 39 & 18/04/18 (LS) \\
\hline Diatoms & Fragilaria & 8 & 7 & 16/11/18 (LS) \\
\hline Diatoms & Pseudo-nitzschia & 40 & 40 & 01/12/20 (BS) \\
\hline Diatoms & Synedra & 24 & 24 & 18/04/18 (LS) \\
\hline Dinoflagellates & Peridinium & $0^{\dagger}$ & 20 & 16/11/18 (LS) \\
\hline Dinoflagellates & Ceratium & $0^{\dagger}$ & 13 & 25/08/18 (LS) \\
\hline Desmids & Staurastrum & 42 & 42 & 16/11/18 (LS) \\
\hline Chlorophyta & Eudorina & 12 & 12 & 25/08/18 (LS) \\
\hline Chrysophyta & Dinobryon & $1^{\ddagger}$ & 1 & 25/08/18 (LS) \\
\hline
\end{tabular}

* LS - Lake Stechlin (freshwater), BS - Baltic Sea (coastal)

$\dagger$ Brightly CFW-stained thecae obscured the visualization of associated sporangia

$\$$ Cellulosic lorica of the host were also stained with CFW

phytoplankton cells or higher fungi [39, 61]. After Lugol fixation, the mucilage likely dispersed, allowing for the positive WGA-staining (Fig. 3). In support of this observation, lectin binding has been shown to improve after chemical treatment (e.g., $\mathrm{KOH}$ or trypsin hydrolysis) which unmasks the mucilage on higher fungi (Fusarium) and the human placenta [61, 62], while $\mathrm{KOH}$ has also been used previously during CFWbased chytrid staining [63]. Similarly, WGA was shown to stain intracellular rhizoids in empty frustules of Asterionella but not in live cells [39], indicating that WGA poorly penetrates through intact cell walls and membranes. CFW is instead a comparably small hydrophilic molecule $(\sim 1 \mathrm{kDa})$ which may more easily interfuse gelatinous layers and cell structures, as indicated by the positive CFW staining in live cells (Figure S2). Sample fixation is, therefore, more crucial for WGA than for CFW staining, and we recommend fixing the samples for a couple of hours (overnight) before microscopy, to allow for an effective WGA binding to the fungal cell walls.

Rhizoids were WGA stained in five out of nine systems, while CFW stained those in only three systems (Fig. 2). In the remaining systems, the rhizoids were likely unbranched and rather short, and thus, their visualization may require a higher resolution technique than light microscopy, such as transmission electron microscopy [44]. In a few instances, encysted and im-/mature sporangia, and stalks were stained less effectively with WGA than with CFW, even after sample fixation (Fig. 2). Besides the mentioned mucilage, which may partly remain after Lugol fixation, WGA binding was potentially hampered by a multi-layered structure of the fungal cell wall. In higher fungi (Aspergillus, Cryptococcus, and Saccharomyces), cell walls can consist of two layers of which the outer layer is without chitin [64, 65], while the inner layer includes chitin, but the chitin-binding sites are presumably poorly accessible to WGA. The observed differential pattern in WGA-staining between species and even between different morphological features of the same species may thus result from cell coatings with carbohydrates, multilayered cell wall structure [60], and/or variable contents of $\mathrm{N}$-acetylglucosamine in chytrid cell walls, potentially limiting the WGA-binding. Differential staining patterns in WGA vs. CFW stained cells, and live vs. fixed samples could therefore indicate differences in chytrid taxonomy and morphology.

In previous studies, a wide range of dye concentrations has been applied to visualize fungal cell walls $-3-50 \mu \mathrm{g}$ WGA mL ${ }^{-1}[37,39,41,62,66,67]$ and $25-10,000 \mu \mathrm{g}$ CFW mL ${ }^{-1}[37-39,41,66,68]$. By comparison, we tested concentrations in the lower range $\left(1,5\right.$, and $\left.25 \mu \mathrm{g} \mathrm{mL}^{-1}\right)$. The lowest concentration $\left(1 \mu \mathrm{g} \mathrm{mL}{ }^{-1}\right)$, and hence the most cost-efficient option, was sufficient for both WGA and CFWbased identification and enumeration of chytrid sporangia (Fig. 4A). The appropriate dye concentration may, however, depend on the chitin concentration in the water. We thus 
recommend $5 \mu \mathrm{g}$ dye $\mathrm{mL}^{-1}$, as chitin concentrations in natural waters are expected to be in the lower $\mu \mathrm{g} \mathrm{mL}^{-1}$ range [69]. CFW-stained chytrids were difficult to distinguish from the background fluorescence on PC filters after staining with $1 \mu \mathrm{g} \mathrm{CFW} \mathrm{mL}{ }^{-1}$, and even indistinguishable from the background at 5 and $25 \mu \mathrm{g} \mathrm{CFW} \mathrm{mL}^{-1}$. Rasconi et al. [38] reported that chytrids were still visible on filters that were stained with $35 \mu \mathrm{g} \mathrm{CFW} \mathrm{mL} \mathrm{m}^{-1}$, but also mentioned that higher dye concentrations precluded any accurate assessment of sporangia.

Inspecting chytrid infections in Utermöhl chambers was beneficial for the host-parasite recognition since (1) the contrast between fungal cell walls and the background fluorescence was more distinct in Utermöhl chambers than on filters, and (2) host cells and their associated parasites could be inspected in parallel under the bright field and fluorescence channels. In this way, also non-fluorescent structures of the phytoplankton host (e.g., silica frustules, spines, or flagella) were visible in Utermöhl chambers, whereas those morphological structures were poorly visible on filters. Moreover, Lugol is less toxic than PFA, and Utermöhl chambers are the standard tool in phytoplankton ecology and monitoring [70]. Accordingly, chytrid staining in those chambers can be readily implemented in, e.g., phytoplankton monitoring programs. The host's autofluorescence was well preserved in PFA-fixed cells (as compared to Lugolfixed cells), which we stored on filters, while PFA-fixation is also applicable to liquid samples and subsequent flow cytometry. Filters can furthermore be stored long-termed at $-20^{\circ} \mathrm{C}$, even after microscopy, and filter samples are well compatible with bacterial enumeration and identification assays $[11,71]$.

\section{Cross-Reactivity and False Positives}

CFW binds to beta-1,4 or 1,3-linked polysaccharide polymers, as present in chitin but also in cellulose, keratin, collagen, and elastin [72]. CFW thus, as a critical disadvantage, stains cellulosic cell walls of multiple phytoplankton groups, including thecate dinoflagellates and some desmids and diatoms [39, 66, 73, 74]. Likewise, in our field samples, the cellulosic theca of Peridinium and Ceratium (dinoflagellates) were brightly stained with $\mathrm{CFW}$, preventing the visualization of their associated sporangia (Table 2, Supplementary Figure S3). This may explain the hitherto relatively few observations of chytrids associated with dinoflagellates, and if they were detected, dinoflagellates had lost their thecae at advanced infection stages [75-77]. Moreover, CFW binds to the cellulosic cell walls of oomycetes $[37,78]$, which can be misidentified as chytrids. Oomycetes and chytrids are dissimilar in their taxonomy (oomycetes are grouped into stramenopiles, together with diatoms) [79]. Yet, both resemble each other in their morphology and lifestyle since the partly globose, ovoid sporangia and free-swimming zoospores of oomycetes can parasitize phytoplankton, similar to chytrids. As a distinction, however, sporangia of oomycetes are mostly endobiotic (develop inside the host cell), in contrast to the mostly epibiotic sporangia of chytrids [80]. WGA usually does not stain oomycetes since their cell walls lack chitin, but traces of chitin $[79,81]$ and a rare case of WGAstaining on oomycetes have been reported [82]. Parasites belonging to the fungi(-like) lineages Cryptomycota and Aphelida may also be misidentified as chytrids. Yet, there is mounting evidence that parasitic Cryptomycota often lack chitinous cell walls $[83,84]$ and act as hyperparasites of chytrids rather than as parasites of phytoplankton [85], while Aphelida are mostly known as endobiotic parasites of phytoplankton [86], like oomycetes. Extracellular infective cysts of Cryptomycota and Aphelida, however, can contain chitin and show positive WGA-staining $[87,88]$. We additionally detected WGA-stained choanoflagellates in association with phytoplankton cells, as shown previously $[89,90]$, and also a positive CFW staining of those flagellates can be expected [90]. Choanoflagellates, however, are distinct in their morphology, with their funnel-shaped collar and ovoid/spherical basal cell body (Figure S4).

WGA cross-reacts with $\mathrm{N}$-acetylglucosamine residues in the peptidoglycan layer of Gram-positive bacteria [91]. Yet, those bacteria are mostly smaller $(1-2 \mu \mathrm{m})$ than sporangia (5-30 $\mu \mathrm{m}$, if matured), and their false identification can be avoided by DAPI-counterstaining, to confirm that the target cell is a eukaryote with a distinct DNA-containing nucleus [41]. WGA staining can moreover be combined with other fluorescent dyes, e.g., during CARD-FISH [11, 71], as various WGA conjugates (with different wavelengths) are commercially available. CFW emits blue light after UV excitation, and it therefore overlaps with DAPI, making DAPI co-staining not applicable, but co-staining with the alternative nucleic acid stain SYTOX green has been applied successfully [92].

During our field sampling, we used neutral and acidic Lugol for sample preservation and realized a $\mathrm{pH}$ effect on the staining pattern. That is, we observed loosely aggregated flocs that were stained with WGA when using acidic instead of neutral Lugol (final $\mathrm{pH}$ in the samples was 4 and 7, respectively, Supplementary Figure S5). This pH effect was less prominent for $\mathrm{CFW}$, i.e., flocs were stained neither at acidic nor neutral $\mathrm{pH}$. We thus recommend using neutral or alkaline instead of acidic Lugol for observing chytrids. Yet, neutral or alkaline Lugol preserve the silica cell walls of diatoms less well than acidic Lugol, and thus short storage times should be considered, while the preservation of coccolithophorids requires neutral/alkaline Lugol because of their calcareous coccoliths [93]. In conclusion, the staining with CFW and WGA is broadly applicable to various study designs, but stain-specific advantages and disadvantages need to be considered (summarized in Table 3). 
Table 3 Advantages (+) and disadvantages (-) of CFW and WGA staining for the detection of chytrids

\begin{tabular}{|c|c|c|c|c|}
\hline & & CFW & & WGA \\
\hline Binding specificity & \pm & $\begin{array}{l}\text { non-specific fluorochrome that binds to beta- }(1,4) \\
\text { and (1.3)-glucans, including chitin }\end{array}$ & + & $\begin{array}{l}\text { chitin-binding lectin, which specifically binds to } \\
\mathrm{N} \text {-acetyl-D-glucosamine (in chitin) and } \mathrm{N} \text {-acetyl- } \\
\text { D-neuraminic (sialic) acid residues }\end{array}$ \\
\hline \multirow[t]{4}{*}{ Cross-reactivity } & - & $\begin{array}{l}\text { cross-reactivity with cellulose, chitosan, keratin, } \\
\text { collagen, and elastin }\end{array}$ & - & $\begin{array}{l}\text { cross-reactivity with peptidoglycan layer of Gram- } \\
\text { positive bacteria }\end{array}$ \\
\hline & - & $\begin{array}{l}\text { binding affinity to cellulosic cell walls of phyto- } \\
\text { plankton can hamper a successful distinction } \\
\text { between phytoplankton cells and associated } \\
\text { sporangia }\end{array}$ & & \\
\hline & - & $\begin{array}{l}\text { oomycetes with cellulosic cell walls can be misi- } \\
\text { dentified as chytrids }\end{array}$ & & \\
\hline & - & binding to cell walls of choanoflagellates expected & - & binding to cell walls of choanoflagellates observed \\
\hline \multirow[t]{4}{*}{ Staining efficiency* } & + & Sporangia: $88-100 \%$ & - & Sporangia: $0-100 \%$ \\
\hline & - & Rhizoids: $0-100 \%$ & + & Rhizoids: $100 \%$ \\
\hline & + & Resting spores: $100 \%$ & - & Resting spores: $8-100 \%$ \\
\hline & + & Stalks: $80-100 \%$ & - & Stalks: $0-100 \%$ \\
\hline Fluorescence & - & fixed wavelength $\left(\mathrm{Ex}_{\max } / \mathrm{Em}_{\max } 355 / 433 \mathrm{~nm}\right)$ & + & $\begin{array}{l}\text { flexible wavelengths: WGA lectins are commercially } \\
\text { available with different conjugated fluorophores } \\
\text { (e.g., Alexa-Fluor } 350,488,555,647 \text {, etc., Fluo- } \\
\text { rescein) }\end{array}$ \\
\hline Co-staining & + & $\begin{array}{l}\text { DAPI co-staining is not possible (but co-staining } \\
\text { with SYTOX green has been applied) }\end{array}$ & + & $\begin{array}{l}\text { DAPI co-staining possible, combined applications } \\
\text { with CARD-FISH have been published }\end{array}$ \\
\hline \multirow[t]{3}{*}{ Sample preparation } & + & Utermöhl chambers: good applicability & + & Utermöhl chambers: good applicability \\
\hline & - & $\begin{array}{l}\text { PC filters: limited applicability (high } \\
\text { background already at } 1 \mu \mathrm{g} \mathrm{CFW} \mathrm{mL}^{-1} \text { ) }\end{array}$ & + & $\begin{array}{l}\text { PC filters: good applicability (moderate } \\
\text { background even at } 25 \mu \mathrm{g} \text { WGA } \mathrm{mL}^{-1} \text { ) }\end{array}$ \\
\hline & \pm & Flow cytometry: not tested herein & + & Flow cytometry: good applicability \\
\hline \multirow[t]{3}{*}{ Sample fixation } & + & $\begin{array}{l}\text { live, non-fixed cells: successful staining of spo- } \\
\text { rangia }\end{array}$ & - & $\begin{array}{l}\text { live, non-fixed: partly unsuccessful staining of } \\
\text { mature sporangia (limited accessibility to WGA } \\
\text { binding sites) }\end{array}$ \\
\hline & + & $\begin{array}{l}\text { Lugol and PFA-preserved cells: successful staining } \\
\text { of sporangia }\end{array}$ & + & $\begin{array}{l}\text { Lugol and PFA-preserved cells: successful staining } \\
\text { of sporangia }\end{array}$ \\
\hline & + & $\begin{array}{l}\text { acidic Lugol did not induce formation/visualization } \\
\text { of unspecific CFW-stained flocs }\end{array}$ & - & $\begin{array}{l}\text { acidic Lugol induced formation/visualization of } \\
\text { unspecific WGA-stained flocs (neutral/alkaline } \\
\text { Lugol preferable) }\end{array}$ \\
\hline \multirow[t]{2}{*}{ Storage } & + & room temperature & - & $\begin{array}{l}-20^{\circ} \mathrm{C} \text {, repeated freeze/thawing cycles should be } \\
\text { avoided }\end{array}$ \\
\hline & + & long-term storage (>1 year) & + & $\begin{array}{l}\text { stable for at least one year (manufacturer instruc- } \\
\text { tions) }\end{array}$ \\
\hline Costs & + & inexpensive (0.10 USD per $1 \mathrm{~mL}$ sample) & + & inexpensive ( 0.40 USD per $1 \mathrm{~mL}$ sample) \\
\hline
\end{tabular}

*Based on entirely/partly stained features as shown in Fig. 2

\pm indicates a neutral evaluation.

\section{Imaging Flow Cytometry}

We validated imaging flow cytometry as a time-efficient, high throughput method to quantify chytrid-phytoplankton associations. The flow cytometer imaged 1,000 host cells within 10-15 min, whereas it took 60-90 min to count 1,300 cells under the microscope. In this way, a large number of cells could be evaluated quickly via flow cytometry, while the measuring capacity of the instrument is even higher $\left(5,000\right.$ particles $\left.\mathrm{s}^{-1}\right)$. Both methods agreed in the obtained host cell abundances and infection prevalence, with a similar accuracy (s.d. of the mean cell abundances was ca. 10\%). As a proof of concept, we successfully separated the Asterionella cells from chytrid sporangia on the flow cytometry images (see Supplementary Figure S6 for an image example), which could be used for automated image analyses. Such automated analyses might be particularly applicable to well-defined, homogeneous co-cultures. Their application on more heterogeneous field-sampled populations, however, is expected to require more advanced algorithms for automated cell distinction and remains to be tested. In addition to cell counting, noninfected and infected phytoplankton cells 
could potentially also be sampled individually via intelligent image-activated cell sorting (iIACS) [94] and thereafter used for, e.g., single-cell genome/transcriptome sequencing.

\section{Recommendations}

Detecting chytrid infections in mixed field populations can be difficult for the untrained eye. To facilitate the screening of chytrids via microscopy, we recommend:

1. CFW-WGA dual staining after cell fixation (overnight), to more reliably identify any cross-reactivities and false positives/negatives, as compared to mono-staining (Table 3, see staining protocol in the supplementary information, Text S2,).

2. Using an inverted microscope, equipped with a bright field and a long-path filter block (e.g., excitation 377/50, emission 415 DAPI LP). Thereby, the sample can concurrently be illuminated/excited with white light and UV light in Utermöhl chambers, visualizing both the phytoplankton host and CFW-stained sporangia (no switching between filter blocks needed).

3. Searching for well-defined globose to ovoid structures (i.e., sporangia with distinct cell walls and little shape irregularity). Those sporangia and their infected host usually display no or little autofluorescence, as compared to non-infected phytoplankton cells (but note that the host's autofluorescence fades within days after Lugol preservation while it is preserved longer by PFA).

4. The re-occurrence of sporangia on the same phytoplankton taxon can be evaluated as a positive sign of chytrid infections since chytrids are often host-specific (at the species or genus level) [85].

Using these guidelines, we detected multiple, partly undescribed chytrid-phytoplankton associations in a freshwater and coastal system (Table 2). Hence, our intercomparison and recommendations shall aid in detecting chytrid infections also in other habitats, to advance our mechanistic and quantitative understanding of the effects of chytrid epidemics on trophic interactions and element cycling in diverse aquatic environments.

Supplementary Information The online version contains supplementary material available at https://doi.org/10.1007/s00248-021-01893-7.

Acknowledgements This work was supported by the German Research Foundation (Emmy Noether Project KL3332/1-1 to IK and the projects WY175/1-1 to SVdW, GR1540/28-1 to HPG, and RA-373/20 to SD). We are grateful to Susanne Busch and the monitoring team at IOW for collecting field samples in the Baltic Sea, and to Kensuke Seto for discussing an earlier draft of this study. We thank the reviewers for their careful proofreading, which contributed to the final outcome of this study.
Author Contribution I.K. and S.V.d.W. designed the study, collected samples, acquired, processed, and interpreted data, and drafted the manuscript. S.D. led the imaging flow cytometry analyses, H.P.G. provided space and instrumentation for culturing, sampling, and microscopy. All authors provided input for data interpretation, revised the manuscript, and approved the final version.

Funding Open Access funding enabled and organized by Projekt DEAL.

Data Availability Data shown in Figure 2 and the ImageJ scripts used for image analyses (data in Figure 4 and S6) are achieved in the openaccess PANGAEA database (https://www.pangaea.de/).

Code Availability Not applicable.

\section{Declarations}

Ethics Approval Not applicable.

Conflict of Interest The authors declare no competing interests.

Open Access This article is licensed under a Creative Commons Attribution 4.0 International License, which permits use, sharing, adaptation, distribution and reproduction in any medium or format, as long as you give appropriate credit to the original author(s) and the source, provide a link to the Creative Commons licence, and indicate if changes were made. The images or other third party material in this article are included in the article's Creative Commons licence, unless indicated otherwise in a credit line to the material. If material is not included in the article's Creative Commons licence and your intended use is not permitted by statutory regulation or exceeds the permitted use, you will need to obtain permission directly from the copyright holder. To view a copy of this licence, visit http://creativecommons.org/licenses/by/4.0/.

\section{References}

1. Lafferty KD, Allesina S, Arim M, Briggs CJ, De Leo G et al (2008) Parasites in food webs: the ultimate missing links. Ecol Lett 11:533-546

2. Bjorbækmo MFM, Evenstad A, Røsæg LL, Krabberød AK, Logares $\mathrm{R}$ (2020) The planktonic protist interactome: where do we stand after a century of research? ISME J 14:544-559

3. Lima-Mendez G, Faust K, Henry N, Decelle J, Colin S et al (2015) Determinants of community structure in the global plankton interactome. Science 348:1262073

4. Falkowski P (2012) Ocean Science: The power of plankton. Nature 483:17-20

5. Reynolds CS (2006) Mortality and loss processes in phytoplankton. In: Reynolds CS (ed) The Ecology of Phytoplankton. Cambridge University Press, Cambridge, pp 239-301

6. Frenken T, Alacid E, Berger SA, Bourne EC, Gerphagnon M et al (2017) Integrating chytrid fungal parasites into plankton ecology: research gaps and needs. Environ Microbiol 19:3802-3822

7. Sime-Ngando T (2012) Phytoplankton chytridiomycosis: Fungal parasites of phytoplankton and their imprints on the food web dynamics. Front Microbiol 3:1-13

8. Canter HM, Lund JWG (1951) Studies on plankton parasites: III. Examples of the interaction between parasitism and other factors determining the growth of diatoms. Ann Bot 15:359-371

9. van Donk E, Ringelberg J (1983) The effect of fungal parasitism on the succession of diatoms in Lake Maarsseveen I (The Netherlands). Freshwat Biol 13:241-251 
10. Gsell AS, De Senerpont Domis LN, Verhoeven KJF, Van Donk E, Ibelings BW (2013) Chytrid epidemics may increase genetic diversity of a diatom spring-bloom. ISME J 7:2057-2059

11. Klawonn I, Van den Wyngaert S, Parada AE, Arandia-Gorostidi N, Whitehouse MJ, Grossart H-P, Dekas AE (2021) Characterizing the "fungal shunt": Parasitic fungi on diatoms affect carbon flow and bacterial communities in aquatic microbial food webs. Proc. Natl. Acad. Sci. USA 118:e2102225118

12. Kagami M, Miki T, Takimoto G (2014) Mycoloop: Chytrids in aquatic food webs. Front Microbiol 5:166

13. Ibelings BW, Gsell AS, Mooij WM, Van Donk E, Van Den Wyngaert S, De Senerpont Domis LN (2011) Chytrid infections and diatom spring blooms: Paradoxical effects of climate warming on fungal epidemics in lakes. Freshwat Biol 56:754-766

14. Gsell AS, De Senerpont Domis LN, Naus-Wiezer SMH, Helmsing NR, Van Donk E, Ibelings BW (2013) Spatiotemporal variation in the distribution of chytrid parasites in diatom host populations. Freshwat Biol 58:523-537

15. Gleason FH, Jephcott TG, Küpper FC, Gerphagnon M, SimeNgando T, Karpov SA, Guillou L, van Ogtrop FF (2015) Potential roles for recently discovered chytrid parasites in the dynamics of harmful algal blooms. Fungal Biol Rev 29:20-33

16. Carney LT, Lane TW (2014) Parasites in algae mass culture. Front Microbiol 5:1-8

17. Shurin JB, Abbott RL, Deal MS, Kwan GT, Litchman E, McBride RC, Mandal S, Smith VH (2013) Industrial-strength ecology: trade-offs and opportunities in algal biofuel production. Ecol Lett 16:1393-1404

18. Grossart H-P, Van den Wyngaert S, Kagami M, Wurzbacher C, Cunliffe M, Rojas-Jimenez K (2019) Fungi in aquatic ecosystems. Nat Rev Microbiol 17:339-354

19. Laundon, D., Cunliffe, M. (2021). A call for a better understanding of aquatic chytrid biology. Frontiers in Fungal Biology 2.

20. Canter HM, Lund JWG (1948) Studies on plankton parasites: I. Fluctuations in the numbers of Asterionella formosa Hass. in relation to fungal epidemics. New Phytol 47:238-261

21. Ortiz-Álvarez R, Triadó-Margarit X, Camarero L, Casamayor EO, Catalan J (2018) High planktonic diversity in mountain lakes contains similar contributions of autotrophic, heterotrophic and parasitic eukaryotic life forms. Sci Rep. 8:4457

22. Taylor JD, Cunliffe M (2016) Multi-year assessment of coastal planktonic fungi reveals environmental drivers of diversity and abundance. ISME J 10:2118-2128

23. Gutiérrez MH, Garcés DV, Pantoja S, González RR, Quiñones RA (2017) Environmental fungal diversity in the upwelling ecosystem off central Chile and potential contribution to enzymatic hydrolysis of macromolecules in coastal ecotones. Fungal Ecol 29:90-95

24. Le Calvez T, Burgaud G, Mahé S, Barbier G, Vandenkoornhuyse $P$ (2009) Fungal diversity in deep-sea hydrothermal ecosystems. Appl Environ Microbiol 75:6415-6421

25. Rojas-Jimenez K, Grossart H-P, Cordes E, Cortés J (2020) Fungal communities in sediments along a depth gradient in the Eastern Tropical Pacific. Front Microbiol 11:1-9

26. Rojas-Jimenez K, Wurzbacher C, Bourne EC, Chiuchiolo A, Priscu JC, Grossart HP (2017) Early diverging lineages within Cryptomycota and Chytridiomycota dominate the fungal communities in ice-covered lakes of the McMurdo Dry Valleys. Antarctica. Sci Rep. 7:15348

27. Hassett BT, Ducluzeau ALL, Collins RE, Gradinger R (2017) Spatial distribution of aquatic marine fungi across the western Arctic and sub-arctic. Environ Microbiol 19:475-484

28. Comeau AM, Vincent WF, Bernier L, Lovejoy C (2016) Novel chytrid lineages dominate fungal sequences in diverse marine and freshwater habitats. Sci Rep 6:30120
29. Gao Z, Johnson ZI, Wang G (2009) Molecular characterization of the spatial diversity and novel lineages of mycoplankton in Hawaiian coastal waters. ISME J 4:111-120

30. Kilias ES, Junges L, Šupraha L, Leonard G, Metfies K, Richards TA (2020) Chytrid fungi distribution and co-occurrence with diatoms correlate with sea ice melt in the Arctic Ocean. Communications Biology 3:183

31. Hassett BT, Gradinger R (2016) Chytrids dominate arctic marine fungal communities. Environ Microbiol 18:2001-2009

32. Bruning K, Lingeman R, Ringelberg J (1992) Estimating the impact of fungal parasites on phytoplankton populations. Limnol Oceanogr 37:252-260

33. Maier MA, Peterson TD (2016) Enumeration of parasitic chytrid zoospores in the Columbia River via quantitative PCR. Appl Environ Microbiol 82:3857

34. Wurzbacher C, Grossart HP (2012) Improved detection and identification of aquatic fungi and chitin in aquatic environments. Mycologia 104:1267-1271

35. Jobard M, Rasconi S, Sime-Ngando T (2010) Fluorescence in situ hybridization of uncultured zoosporic fungi: Testing with cloneFISH and application to freshwater samples using CARD-FISH. J Microbiol Methods 83:236-243

36. Hassett BT, Borrego EJ, Vonnahme TR, Rämä T, Kolomiets MV, Gradinger R (2019) Arctic marine fungi: biomass, functional genes, and putative ecological roles. ISME J 13:1484-1496

37. Scholz B, Küpper FC, Vyverman W, Karsten U (2014) Eukaryotic pathogens (Chytridiomycota and Oomycota) infecting marine microphytobenthic diatoms - a methodological comparison. J Phycol 50:1009-1019

38. Rasconi S, Jobard M, Jouve L, Sime-Ngando T (2009) Use of calcofluor white for detection, identification, and quantification of phytoplanktonic fungal parasites. Appl Environ Microbiol 75:2545

39. Mueller U, Von Sengbusch P (1983) Visualization of aquatic fungi (Chytridiales) parasitizing on algae by means of induced fluorescence. Archiv Hydrobiologie 97:471-485

40. Laundon D, Chrismas N, Wheeler G, Cunliffe M (2020) Chytrid rhizoid morphogenesis resembles hyphal development in multicellular fungi and is adaptive to resource availability. Proc R Soc B Biol Sci 287:20200433

41. Richards TA, Leonard G, Mahé F, Del Campo J, Romac S et al (2015) Molecular diversity and distribution of marine fungi across 130 european environmental samples. Proc R Soc B Biol Sci 282:20152243

42. Pomroy AJ (1984) Direct counting of bacteria preserved with lugol iodine solution. Appl Environ Microbiol 47:1191-1192

43. Seto K, Van den Wyngaert S, Degawa Y, Kagami M (2020) Taxonomic revision of the genus Zygorhizidium: Zygorhizidiales and Zygophlyctidales ord. nov. (Chytridiomycetes, Chytridiomycota). Fungal Syst Evol 5:17-38

44. Van den Wyngaert S, Seto K, Rojas-Jimenez K, Kagami M, Grossart HP (2017) A new parasitic chytrid, Staurastromyces oculus (Rhizophydiales, Staurastromycetaceae fam. Nov.), infecting the freshwater desmid Staurastrum sp. Protist 168:392-407

45. Van den Wyngaert S, Rojas-Jimenez K, Seto K, Kagami M, Grossart HP (2018) Diversity and hidden host specificity of chytrids infecting colonial volvocacean algae. J Eukaryot Microbiol 65:870-881

46. Doggett MS, Porter D (1996) Sexual reproduction in the fungal parasite, Zygorhizidium planktonicum. Mycologia 88:720-732

47. Schneider CA, Rasband WS, Eliceiri KW (2012) NIH Image to ImageJ: 25 years of image analysis. Nat Methods 9:671-675

48. Dunker S (2019) Hidden secrets behind dots: Improved phytoplankton taxonomic resolution using high-throughput imaging flow cytometry. Cytometry A 95:854-868 
49. Dunker S (2020) Imaging flow cytometry for phylogenetic and morphologically-based functional group clustering of a natural phytoplankton community over 1 year in an urban pond. Cytometry A 97:727-736

50. Lefèvre E, Roussel B, Amblard C, Sime-Ngando T (2008) The molecular diversity of freshwater picoeukaryotes reveals high occurrence of putative parasitoids in the plankton. PLOS ONE 3:e2324

51. Kagami M, Amano Y, Ishii N (2012) Community structure of planktonic fungi and the impact of parasitic chytrids on phytoplankton in Lake Inba. Japan Microb Ecol 63:358-368

52. Rojas-Jimenez K, Rieck A, Wurzbacher C, Jürgens K, Labrenz M, Grossart H-P (2019) A salinity threshold separating fungal communities in the Baltic Sea. Front Microbiol 10:1-9

53. Wurzbacher C, Warthmann N, Bourne E, Attermeyer K, Allgaier $M$ et al (2016) High habitat-specificity in fungal communities in oligo-mesotrophic, temperate Lake Stechlin (North-East Germany). MycoKeys 16:17-44

54. Canter HM, Lund JWG (1969) The parasitism of planktonic desmids by fungi. Österreichische botanische Zeitschrift 116:351-377

55. Passow U, Alldredge AL, Logan BE (1994) The role of particulate carbohydrate exudates in the flocculation of diatom blooms. DeepSea Research Part I 41:335-357

56. Kiørboe T, Hansen JLS (1993) Phytoplankton aggregate formation: observations of patterns and mechanisms of cell sticking and the significance of exopolymeric material. J Plankton Res 15:993-1018

57. Decho AW, Gutierrez T (2017) Microbial extracellular polymeric substances (EPSs) in ocean systems. Front Microbiol 8:1-28

58. Passow U (2002) Transparent exopolymer particles (TEP) in aquatic environments. Prog Oceanogr 55:287-333

59. Alldredge AL, Passow U, Logan BE (1993) The abundance and significance of a class of large, transparent organic particles in the ocean. Deep-Sea Res Pt I 40:1131-1140

60. Powell MJ (1994) Production and modifications of extracellular structures during development of chytridiomycetes. In: Wetherbee R, Pickett-Heaps JD, Andersen RA (eds) The Protistan Cell Surface. Springer Vienna, Vienna, pp 123-141

61. Kleinschuster SJ, Baker R (1974) Lectin-detectable differences in carbohydrate-containing surface moieties of macroconidia of Fusarium roseum 'avenaceum' and Fusarium solani. Phytopathology 64:394-399

62. Høyer PE, Kirkeby S (1996) The impact of fixatives on the binding of lectins to $\mathrm{N}$-acetyl-glucosamine residues of human syncytiotrophoblast: a quantitative histochemical study. J Histochem Cytochem 44:855-863

63. Kagami M, Van Donk E, De Bruin A, Rijkeboer M, Ibelings BW (2004) Daphnia can protect diatoms from fungal parasitism. Limnol Oceanogr 49:680-685

64. Garcia-Rubio R, de Oliveira HC, Rivera J, Trevijano-Contador N (2020) The fungal cell wall: Candida, Cryptococcus, and Aspergillus species. Front Microbiol 10:1-13

65. Klis FM, Mol P, Hellingwerf K, Brul S (2002) Dynamics of cell wall structure in Saccharomyces cerevisiae. FEMS Microbiol Rev 26:239-256

66. Meyberg M (1988) Selective staining of fungal hyphae in parasitic and symbiotic plant-fungus associations. Histochemistry 88:197-199

67. P. v. Sengbusch, M. Mix, I. Wachholz, E. Manshard, (1982) FITClabeled lectins and calcofluor white ST as probes for the investigation of the molecular architecture of cell surfaces. Studies on conjugatophycean species Protoplasma 111:38-52

68. Costa-de-Oliveira S, Silva AP, Miranda IM, Salvador A, Azevedo MM, Munro CA, Rodrigues AG, Pina-Vaz C (2013)
Determination of chitin content in fungal cell wall: An alternative flow cytometric method. Cytometry A 83A:324-328

69. Biancalana F, Germán K, Sofía DM, B. Anabela A., F. Anna, G.-C. John E., P. Dieter, L. Rubén, (2017) Chitin determination on marine seston in a shallow temperate estuary (Argentina). Braz J Oceanogr 65:146-154

70. L. Edler, M. Elbrächter (2010) The Utermöhl method for quantitative phytoplankton analysis. In: B. Karlson, C. Cusack, E. Bresnan (ed) Microscopic and molecular methods for quantitative phytoplankton analysis, (Intergovernmental Oceanographic Commission Manuals and Guides UNESCO, Paris) chap. 13-20, pp. 114.

71. Biancalana F, Kopprio GA, Lara RJ, Alonso C (2017) A protocol for the simultaneous identification of chitin-containing particles and their associated bacteria. Syst Appl Microbiol 40:314-320

72. Monheit JE, Cowan DF, Moore DG (1984) Rapid detection of fungi in tissues using calcofluor white and fluorescence microscopy. Arch Pathol Lab Med 108:616-618

73. Durkin CA, Mock T, Armbrust EV (2009) Chitin in diatoms and its association with the cell wall. Eukaryot Cell 8:1038

74. Chambouvet A, Morin P, Marie D, Guillou L (2008) Control of toxic marine dinoflagellate blooms by serial parasitic killers. Science 322:1254

75. Leshem T, Letcher PM, Powell MJ, Sukenik A (2016) Characterization of a new chytrid species parasitic on the dinoflagellate, Peridinium gatunense. Mycologia 108:731-743

76. Karpov SA, Reñé A, Vishnyakov AE, Seto K, Alacid E, Paloheimo A, Kagami M, Kremp A, Garcés E (2021) Parasitoid chytridiomycete Ericiomyces syringoforeus gen. et sp. nov. has unique cellular structures to infect the host. Mycol Prog 20:95-109

77. Lepelletier F, Karpov SA, Alacid E, Le Panse S, Bigeard E, Garcés E, Jeanthon C, Guillou L (2014) Dinomyces arenysensis gen. et sp. nov. (Rhizophydiales, Dinomycetaceae fam. nov.), a chytrid infecting marine dinoflagellates. Protist 165:230-244

78. Garvetto A, Nézan E, Badis Y, Bilien G, Arce P, Bresnan E, Gachon CMM, Siano R (2018) Novel widespread marine oomycetes parasitising diatoms, including the toxic genus Pseudonitzschia: Genetic, morphological, and ecological characterisation. Front Microbiol 9:1-19

79. Latijnhouwers M, de Wit PJ, Govers F (2003) Oomycetes and fungi: similar weaponry to attack plants. Trends Microbiol 11:462-469

80. Scholz B, Guillou L, Marano AV, Neuhauser S, Sullivan BK, Karsten U, Küpper FC, Gleason FH (2016) Zoosporic parasites infecting marine diatoms - A black box that needs to be opened. Fungal Ecol 19:59-76

81. M. Peter (2005) Chitin and Chitosan in Fungi. In: A. Steinbüchel (ed) Biopolymers Online, (Wiley-VCH Verlag GmbH \& Co. KGaA, online) chap. Part 6. Polysaccharides.

82. Badreddine I, Lafitte C, Heux L, Skandalis N, Spanou Z et al (2008) Cell wall chitosaccharides are essential components and exposed patterns of the phytopathogenic oomycete Aphanomyces Euteiches. Eukaryot Cell 7:1980-1993

83. Jones MDM, Forn I, Gadelha C, Egan MJ, Bass D, Massana R, Richards TA (2011) Discovery of novel intermediate forms redefines the fungal tree of life. Nature 474:200-203

84. James TY, Berbee ML (2012) No jacket required - new fungal lineage defies dress code. BioEssays 34:94-102

85. Kagami M, Seto K, Nozaki D, Nakamura T, Wakana H, Wurzbacher C (2021) Single dominant diatom can host diverse parasitic fungi with different degree of host specificity. Limnol Oceanogr 66:667-677

86. Karpov S, Mamkaeva M, Aleoshin V, Nassonova E, Lilje O, Gleason F (2014) Morphology, phylogeny, and ecology of the aphelids (Aphelidea, Opisthokonta) and proposal for the new superphylum Opisthosporidia. Front Microbiol 5:1-11 
87. James TY, Pelin A, Bonen L, Ahrendt S, Sain D, Corradi N, Stajich JE (2013) Shared signatures of parasitism and phylogenomics unite Cryptomycota and microsporidia. Curr Biol 23:1548-1553

88. Torruella G, Grau-Bové X, Moreira D, Karpov SA, Burns JA, Sebé-Pedrós A, Völcker E, López-García P (2018) Global transcriptome analysis of the aphelid Paraphelidium tribonemae supports the phagotrophic origin of fungi. Communications Biology $1: 231$

89. Dayel MJ, Alegado RA, Fairclough SR, Levin TC, Nichols SA, McDonald K, King N (2011) Cell differentiation and morphogenesis in the colony-forming choanoflagellate Salpingoeca rosetta. Dev Biol 357:73-82

90. Müller U, P. v. Sengbusch, (1983) Interactions of species in an Anabaena flos-aquae association from the Plußsee (East-Holstein, Federal Republic of Germany). Oecologia 58:215-219
91. Sizemore RK, Caldwell JJ, Kendrick AS (1990) Alternate gram staining technique using a fluorescent lectin. Appl Environ Microbiol 56:2245

92. Gerphagnon M, Latour D, Colombet J, Sime-Ngando T (2013) A double staining method using SYTOX green and calcofluor white for studying fungal parasites of phytoplankton. Appl Environ Microbiol 79:3943-3951

93. Williams OJ, Beckett RE, Maxwell DL (2016) Marine phytoplankton preservation with Lugol's: a comparison of solutions. J Appl Phycol 28:1705-1712

94. Nitta N, Sugimura T, Isozaki A, Mikami H, Hiraki K et al (2018) Intelligent Image-Activated Cell Sorting. Cell 175:266-276.e213 